\title{
IMPROVING RAINFALL PERFORMANCE BY DECAYING AVERAGE BIAS CORRECTION VIA LYAPUNOV THEORY
}

\author{
Pramet Kaewmesri and Usa Humphries* \\ Department of Mathematics, Faculty of Science, King Mongkut's University of Technology Thonburi \\ (KMUTT), 126 Pracha-Uthit Road, Bang mod, Thung Khru, Thailand, 10140 \\ *Corresponding Author, Received: 03 March 2020, Revised: 18 March 2020, Accepted: 07 April 2020
}

\begin{abstract}
The bias correction is the main tool for improving the rainfall simulation from the model to improve performance and increasing accuracy with observation. Since, if the good estimate and more accuracy of rainfall simulation are crucial to helping the risk assessment policies for increasing demands from agricultural, industrial and domestic sectors for many countries. So, the aim of this study, to improving decaying average bias correction by using the Lyapunov theorem for simulating rainfall over Indochina Peninsular. The time period for exampling the results were in Mar, April, and May 2015. The results were shown a comparison between standalone model simulation results and bias correction results (Theorem 2 and Theorem 3) as shown in time series and statistical method value. The times series results were shown the results from bias correction improving by Lyapunov (Theorem 2 and Theorem 3) that show good estimates than the standalone model simulation. In statistical analysis, the bias correction improving by the Lyapunov theorem (Theorem 2 and Theorem 3) were shown the highest accuracy (MAE and RMSE) than standalone model simulation. However, the results from the time sires and statistical analysis were guaranteed the bias correction improving by the Lyapunov theorem that can improve the results of the model and increase more accuracy when compared with reanalysis grid observation data.
\end{abstract}

Keywords: Bias correction, Rainfall, Lyapunov theorem

\section{INTRODUCTION}

Science has evolved from an attempt to understand and predict the behavior of the universe and the systems within it. Much of this owes to the development of suitable models, which agree with the observations. These models are either in a symbolic form which the humans use or in the mathematical form that is found from physical laws. Most systems are causal, which can be categorized as either static, where the output depends on the current inputs, or dynamic, where the output depends on not only the current inputs but also past inputs and outputs. Many systems also possess unobservable inputs, which cannot be measured, but affect the output of the system, that is time series systems. These inputs are known as disturbances and aggravate the modeling process [1-2].

Lyapunov's second (or direct) method provides tools for studying (asymptotic) stability properties of an equilibrium point of a dynamical system (or systems of differential equations). The intuitive picture is that of a scalar output-function, often thought of as generalized energy that is bounded below, and decreasing along with solutions. If this function has only a single local minimum, and it is strictly decreasing along with all non-equilibrium solutions, then one expects that all solutions tend to that equilibrium where the output function has a minimum. This is indeed correct. In the sequel, we state and prove theorems, including some that relax the requirement of strictly or globally decreasing, and also discuss converse theorems that guarantee the existence of such functions. Much of the power of the method comes from its simplicity - one does not need to know any solutions: Knowing only the differential (or difference) equation one can easily establish whether such an output function is decreasing along with solutions. However, while it is easy to see that for every asymptotically stable system there exists many, even smooth, such Lyapunov functions, in many cases it is almost impossible to get one's hands onto one such Lyapunov function. They are easy to construct for e.g. linear systems, and many strategies are available for special classes - in general, it is a true art to come up with explicit formulas for good candidate Lyapunov functions [1-2].

One of the most challenging problems of increasing the accuracy of rainfall over Indochina Peninsular [3-5]. If increase accuracy of estimating rainfall is crucial to helping the risk assessment policies for increasing demands from agricultural, industrial and domestic sectors for the country over Indochina Peninsular. Therefore, the aim of this study, to improving decaying average bias correction by using the Lyapunov theorem for simulating rainfall over Indochina Peninsular. The time period for exampling the results were in Mar, April, and May 2015. The results from model simulation compared by time series and statistical method with the reanalysis rainfall (Global 
Precipitation Climatology Project Version 2.3) [68].

\section{PRELIMINARIES}

\subsection{Definition and Theorem of Lyapunov function}

Definition 1. A solution $\boldsymbol{x}(\boldsymbol{t})$ is asymptotically stable if it is stable and there is a $\boldsymbol{\rho}>\mathbf{0}$ such that if $\left\|x_{0}-x_{0}\right\|<\rho$ then $\lim _{t \rightarrow 0}\left\|x_{0}-x_{0}\right\|=0$.

Theorem 1. If a Lyapunov function $\boldsymbol{V}(\boldsymbol{t}, \boldsymbol{x})$ exists satisfying:

$1 \boldsymbol{V}(\boldsymbol{t}, \boldsymbol{x})$ is positive definite,

$2 \boldsymbol{V}(\boldsymbol{t}, \boldsymbol{x})$ admits an infinitesimal upper bound,

$3 \boldsymbol{V}(\boldsymbol{t}, \boldsymbol{x})$ is negative definite

Then the solution $\boldsymbol{x}(\boldsymbol{t})$ is asymptotically stable.

\subsection{Decaying average bias correction method}

The operational environment requires that the ensemble postprocessing algorithms be relatively applicable and flexible for implementation. The decaying averaging method applies an adaptive algorithm, and its application includes two steps. The first step is to estimate the first-moment bias with respect to the analysis filed, which is called the decaying averaging mean error. The second step is to remove the error from the ensemble forecasts. Both the bias assessment step and the biascorrection step are carried out separately at each forecast lead time, on each individual grid point and for each initial cycle [9].

\subsubsection{Bias estimate}

The bias estimation is used as a formula form by [9]. It may be written as

$$
b(t)=f(t)-o(t)
$$

where $\boldsymbol{b}(\boldsymbol{t})$ is a bias for each lead-time $\boldsymbol{t} . \boldsymbol{f}(\boldsymbol{t})$ is defined as the rainfall forecast data from the model. $\boldsymbol{o}(\boldsymbol{t})$ is defined as the observation data from reanalysis data.

\subsubsection{Decaying average}

The Decaying average is used as a formula form by [9]. It may be written as

$B(t)=(1-w) \sum_{i=1}^{n} B(t-n)+$ $\boldsymbol{w b}(\boldsymbol{t})$

where $\boldsymbol{B}(\boldsymbol{t})$ will be updated by considering the prior period bias $\boldsymbol{B}(\boldsymbol{t}-\boldsymbol{n})$ and current bias $\boldsymbol{b}(\boldsymbol{t})$ by using the decaying average with weight coefficient $\boldsymbol{w}, \boldsymbol{n}$ is defined as the number of years of $\boldsymbol{i}$ pairs of observation and forecast values.

\subsubsection{Bias Correction}

Bias correction is used as a formula form by [9]. It may be written as

$F(t)=f(t)-B(t)$

where $\boldsymbol{F}(\boldsymbol{t})$ is defined as new bias correction simulation, $\boldsymbol{f}(\boldsymbol{t})$ is defined as current simulation, $\boldsymbol{B}(\boldsymbol{t})$ is defined as the decaying average from eq. 2

\section{DEVELOP DECAYING AVERAGE BIAS CORRECTION METHOD BY LYAPUNOV FUNCTION}

Theorem 2. Give weight coefficient $\mathbf{0}<\boldsymbol{a}<\mathbf{1}$ and $\mathbf{0}<\boldsymbol{w}<\mathbf{1}$. Then, the decaying average equation (2) is asymptotically stable for any time delay $\boldsymbol{B}(\boldsymbol{t}-\mathbf{1})$ satisfying $\boldsymbol{B}(\boldsymbol{t}-\mathbf{1}) \in \boldsymbol{R}$ and $\boldsymbol{b}(\boldsymbol{t}) \in \boldsymbol{R}$, if the following conditions

$$
\begin{array}{r}
2 a[1-w] B(t-1) w b(t)-a B(t-1) \leq \\
0 \ldots .(4)
\end{array}
$$

Proof. Consider the Lyapunov function

$$
\begin{aligned}
V(B(t-1))= & a B^{2}(t-1), \\
\Delta V(B(t-1))= & V B(t)-V B(t-1), \\
= & a[B(t-1)-w B(t-1)+ \\
& w b(t)]^{2}-a B^{2}(t-1), \\
= & a\left[(1-w)^{2} B^{2}(t-1)+\right. \\
& 2(1-w) B(t-1) w b(t)+ \\
& \left.w^{2} b^{2}\right]-a B^{2}(t-1), \\
= & a(1-w)^{2} B^{2}(t-1)+ \\
& 2(1-w) B(t-1) w b(t)+ \\
& a w^{2} b^{2}-a B^{2}(t-
\end{aligned}
$$

1)

In this study, we neglect term $>\mathbf{0}$ in equation 3 that include term $\boldsymbol{a}(\mathbf{1}-\boldsymbol{w})^{\mathbf{2}} \boldsymbol{B}^{\mathbf{2}}(\boldsymbol{t}-\mathbf{1})>\mathbf{0}$ and $\boldsymbol{a} \boldsymbol{w}^{\mathbf{2}} \boldsymbol{b}^{\mathbf{2}}>\mathbf{0}$. So, From Definition 1 and Theorem 1 can conclude $\mathbf{2}(\mathbf{1}-\boldsymbol{w}) \boldsymbol{B}(\boldsymbol{t}-\mathbf{1}) \boldsymbol{w b}(\boldsymbol{t})-$ $a B^{2}(t-1) \leq \mathbf{0}$ condition of asymptotically stable. Then we have a new $\boldsymbol{w} \boldsymbol{b}(\boldsymbol{t})$ that may be written as

$w b(t)=B(t-1) / 2+$

$w^{2} b(t)$ 
Substituting eq 6 into eq 2. So, the new decaying average has used a formula from Theorem 2. It may be written

$$
\begin{aligned}
& B(t)=(0.5-w) \sum_{i=1}^{n} B(t-n)+ \\
& w^{2} b(t) \ldots \ldots .(7)
\end{aligned}
$$

where $\boldsymbol{B}(\boldsymbol{t})$ will be updated by considering the prior period bias $\boldsymbol{B}(\boldsymbol{t}-\boldsymbol{n})$ and current bias $\boldsymbol{b}(\boldsymbol{t})$ by using the decaying average with weight coefficient $\boldsymbol{w}$ and $\boldsymbol{a}, \boldsymbol{n}$ is defined as the number of years of $\boldsymbol{i}$ pairs of observation and forecast values.

Theorem 3. Give weight coefficient $\mathbf{0}<\boldsymbol{a}<$ $\mathbf{1}, \mathbf{0}<\boldsymbol{c}<\mathbf{1}$ and $\mathbf{0}<\boldsymbol{w}<\mathbf{1}$. Then, the decaying average equation (2) is asymptotically stable for any time delay $\boldsymbol{B}(\boldsymbol{t}-\mathbf{1})$ satisfying $\boldsymbol{B}(\boldsymbol{t}-\mathbf{1}) \in \boldsymbol{R}$ and $\boldsymbol{b}(\boldsymbol{t}) \in \boldsymbol{R}$, if the following conditions

$$
\begin{gathered}
2 a[1-w] B(t-1) w b(t)-(a+c) B(t-1) \\
\leq 0
\end{gathered}
$$

Proof. Consider the Lyapunov function

$$
\begin{aligned}
& V(B(t-1))=a B^{2}(t-1), \\
& \Delta V(B(t-1))=V B(t)-V B(t-1), \\
& =a[B(t-1)-w B(t-1)+ \\
& w b(t)]^{2}-a B^{2}(t-1) \\
& =a\left[(1-w)^{2} B^{2}(t-1)+\right. \\
& 2(1-w) B(t-1) w b(t)+ \\
& \left.w^{2} b^{2}\right]-a B^{2}(t-1)- \\
& c B(t-1) \text {, } \\
& =a(1-w)^{2} B^{2}(t-1)+ \\
& 2(1-w) B(t-1) w b(t)+ \\
& a w^{2} b^{2}-a B^{2}(t-1)- \\
& c B(t-1)
\end{aligned}
$$

In this study, we neglect term $>\mathbf{0}$ in equation 3 that include term $\boldsymbol{a}(\mathbf{1}-\boldsymbol{w})^{\mathbf{2}} \boldsymbol{B}^{\mathbf{2}}(\boldsymbol{t}-\mathbf{1})>\mathbf{0}$ and $\boldsymbol{a} \boldsymbol{w}^{2} \boldsymbol{b}^{2}>\mathbf{0}$. From Definition 1 and Theorem 1 can conclud $\quad 2(1-w) B(t-1) w b(t)-a B^{2}(t-$ 1) $-\boldsymbol{c} \boldsymbol{B}(\boldsymbol{t}-\mathbf{1}) \leq \mathbf{0}$ condition of asymptotically stable. Then we have a new $\boldsymbol{w} \boldsymbol{b}(\boldsymbol{t})$ that may be written as

$w b(t)=\frac{1}{2}\left(B(t-1)+\frac{c}{a}\right)+$
$w^{2} b(t) \ldots \ldots \ldots(10)$

Substituting eq 10 into eq 2. So, the new decaying average is used as a formula from Theorem 3. It may be written

where $\boldsymbol{B}(\boldsymbol{t})$ will be updated by considering the prior period bias $\boldsymbol{B}(\boldsymbol{t}-\boldsymbol{n})$ and current bias $\boldsymbol{b}(\boldsymbol{t})$ by
$B(t)=(0.5-w) \sum_{i=1}^{n} B(t-n)-\frac{c}{2 a}+w^{2} b(t)$.

using the decaying average with weight coefficient $\boldsymbol{w}, \boldsymbol{a}$, and $\boldsymbol{c}, \boldsymbol{n}$ is defined as the number of years of $\boldsymbol{i}$ pairs of observation and forecast values.

\section{NUMERICAL RESULTS}

In this study, we used the Lyapunov function to develop decaying average bias correction. The results from the model were used in the bias correction method with Theorem 2 and Theorem 3 from the Institute of Atmospheric Physics Atmospheric General Circulation (IAP-AGCM) model. The IAP-AGCM model was developed from the Institute of Atmospheric Physics Chinese Academy of Science [10] to forecast rainfall over Thailand. In observation data, the global rainfall data was used in this study that was Global Precipitation Climatology Project Version 2.3 (GPCP) data [6-8]. The observation data was developed from the Japan Aerospace Exploration Agency (JAXA) from Japan and the National Aeronautics and Space Administration (NASA) from the United States. The prediction period was estimated in March, April, and May from 20002015. This study, for example, simulating was used 120 grids covering Indochina Peninsular area in March, April and May 2015.

The result from Fig. 1, the comparison rainfall value in March 2015 between results from average members model simulation (orange line) and GPCP observation data (black line). The result from the standalone model was overestimated more than observation data. The bias correction from Theorem 2 (Fig. 2) and Theorem 3 (Fig. 3) are shown a good trend rainfall simulation more than standalone model simulation. The bias correction decreased rainfall to close the observation data. For example, over grid number 15, grid number 25 and grid number 33, the rainfall value of bias correction (Theorem 2 (Fig. 2) and Theorem 3 (Fig. 3)) decrease from around $6 \mathrm{~mm} /$ day to around 4 $\mathrm{mm}$ /day. Furthermore, over grid number 46 to grid number 54. The rainfall of bias correction (Theorem2 and Theorem3) approached observation data than standalone model simulation.

In Fig. 4, the comparison rainfall value in April 2015 between results from average members model simulation (orange line) and GPCP observation data (black line). The result from standalone model was overestimated more than observation data, especially at grid number 43 (around $9 \mathrm{~mm} /$ day), grid number 55 (around 8 $\mathrm{mm} /$ day), grid number 65 (around $9 \mathrm{~mm} /$ day), grid number 75 (around $11 \mathrm{~mm} /$ day), grid number 100 
(around $10 \mathrm{~mm} /$ day). The bias correction (Theorem 2 (Fig. 5) and Theorem 3 (Figure 6)) decreased rainfall to close the observation data over grid number 43 (around $7 \mathrm{~mm} /$ day), grid number 55(around $6 \mathrm{~mm} /$ day), grid number 65 (around 7 $\mathrm{mm} /$ day), grid number 75 (around $7 \mathrm{~mm} /$ day), grid number 100 (around $7 \mathrm{~mm} /$ day) that result from bias correction approached observation data than standalone model simulation.

In case May 2015, Figure 7, The result from model was overestimated more than observation data, especially at grid number 43 (around 14 $\mathrm{mm} /$ day), grid number 55 (around $12 \mathrm{~mm} /$ day), grid number 65 (around $13 \mathrm{~mm} /$ day), grid number 75 (around $14 \mathrm{~mm} /$ day), grid number 84 (around 16 $\mathrm{mm} /$ day), grid number 95 (around $16 \mathrm{~mm} /$ day), grid number 108 (around 13 mm/day) and grid number 117 (around $13 \mathrm{~mm} /$ day). The bias correction
(Theorem 2 (Fig. 8) and Theorem 3 (Fig. 9)) were shown good performance than standalone model simulation. Obviously, at grid number 43 (around $10 \mathrm{~mm} /$ day), grid number 55 (around $11 \mathrm{~mm} /$ day), grid number 65 (around $11 \mathrm{~mm} /$ day), grid number 75 (around $12 \mathrm{~mm} /$ day), grid number 84 (around 13 $\mathrm{mm} /$ day), grid number 95 (around $13 \mathrm{~mm} /$ day), grid number 112 (around $10 \mathrm{~mm} /$ day) and grid number 117 (around $9 \mathrm{~mm} /$ day). From the results, we can conclude the results from bias correction (Theorem 2 and Theorem 3 ) that improved the results from the model and can approve the results closely than model simulation. However, that was confirm the bias correction to show better results than model simulation. So, in the next step, the statistical analysis confirm the results from bias correction that shown good results than model simulation.

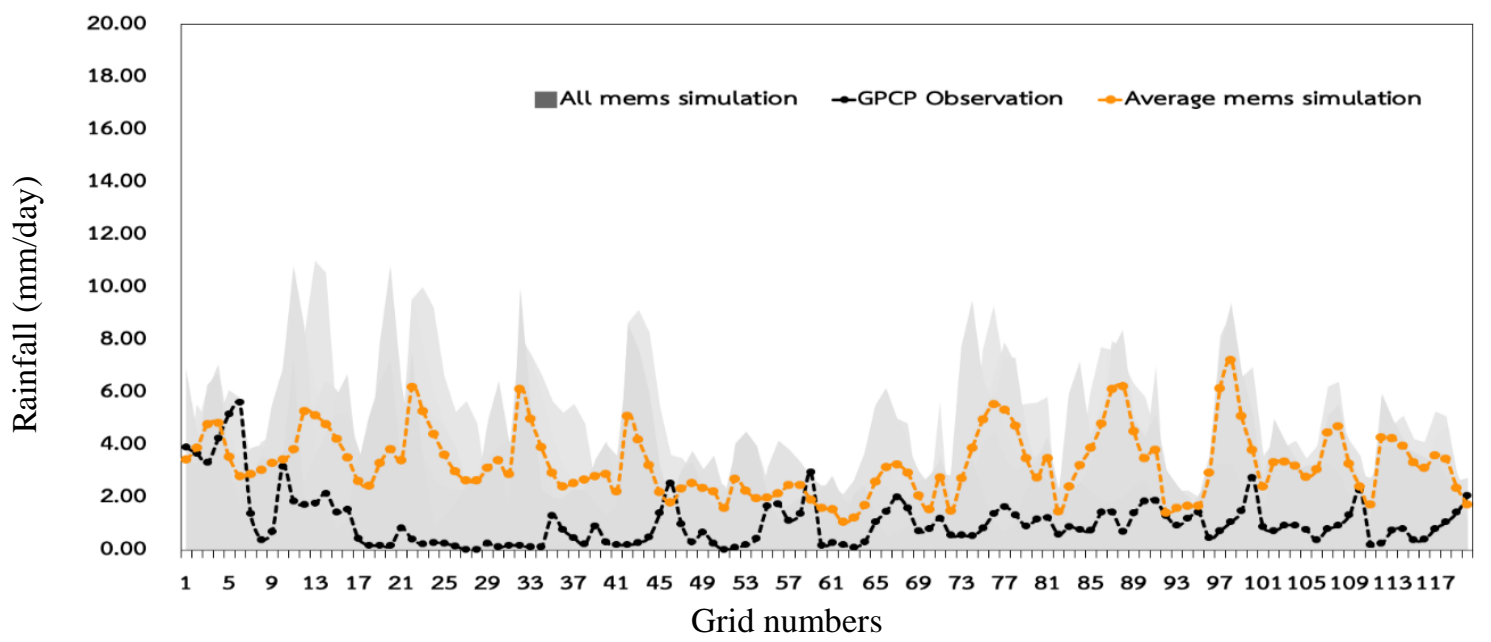

Fig. 1 The comparison rainfall value on March 2015 between results from average members model simulation (orange line) and GPCP observation data (black line)

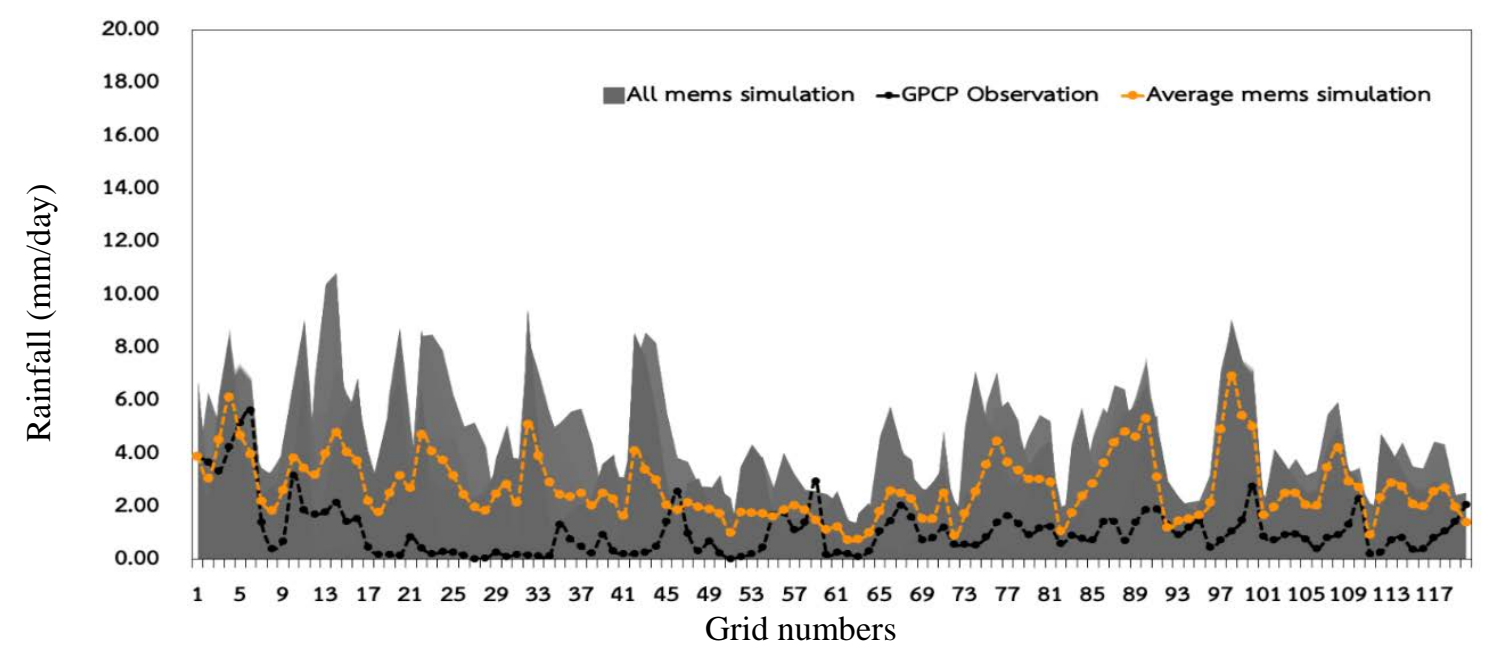

Fig. 2 The comparison rainfall value on March 2015 between results from average members bias correction Theorem 2 simulation (orange line) and GPCP observation data (black line) 


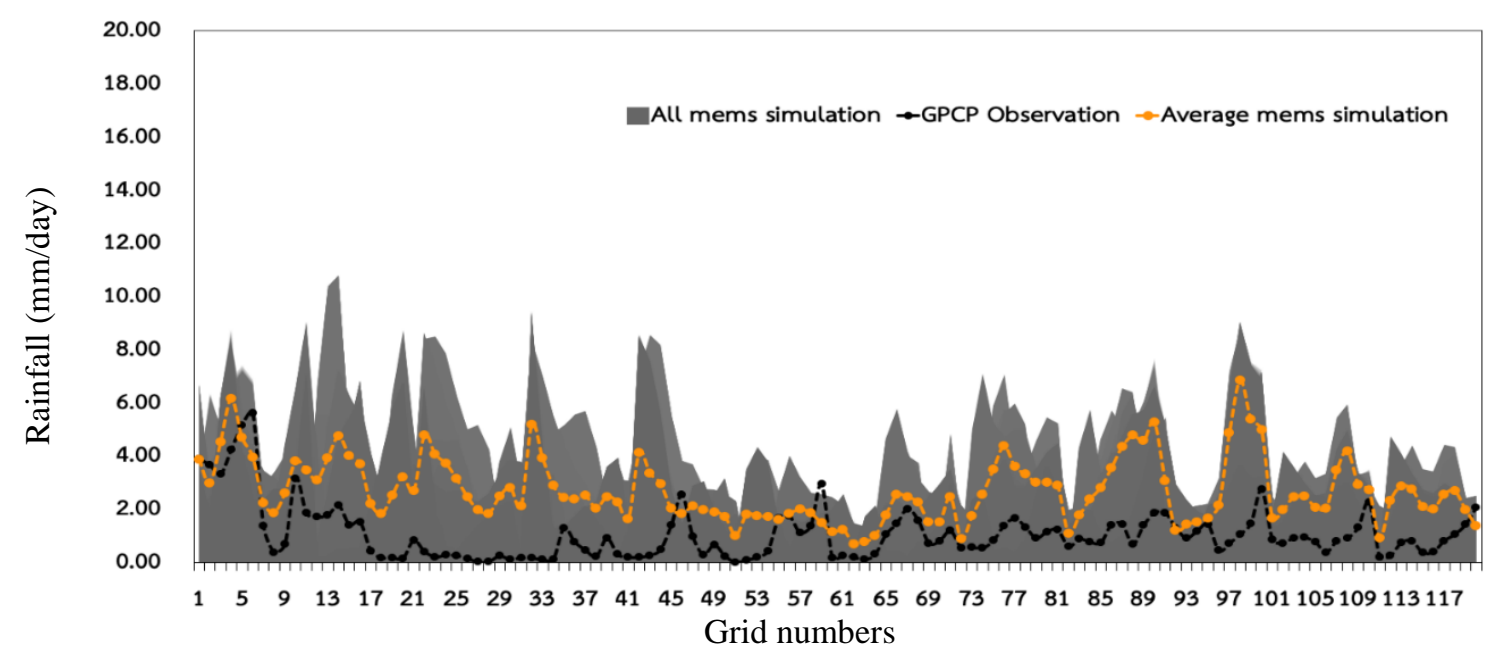

Fig. 3 The comparison rainfall value on March 2015 between results from average members bias correction Theorem 3 simulation (orange line) and GPCP observation data (black line)

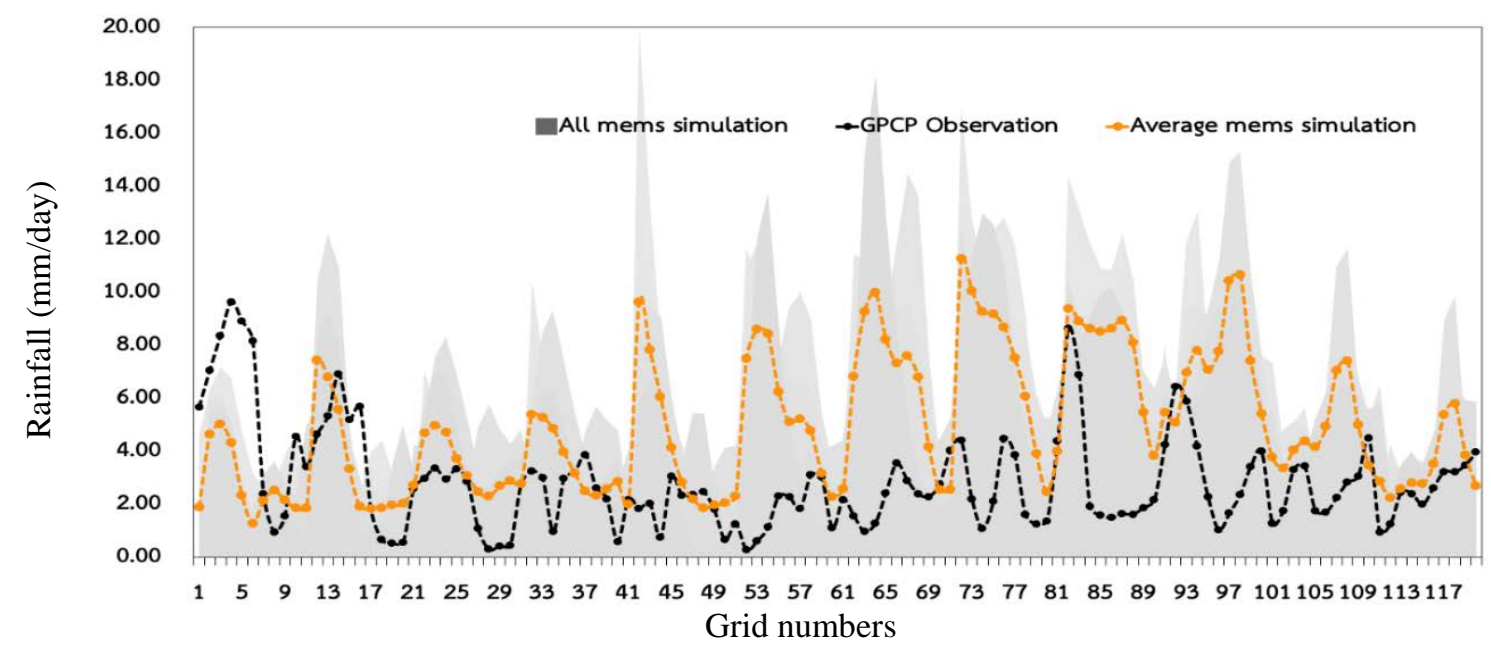

Fig. 4 The comparison rainfall value on April 2015 between results from average members model simulation (orange line) and GPCP observation data (black line)

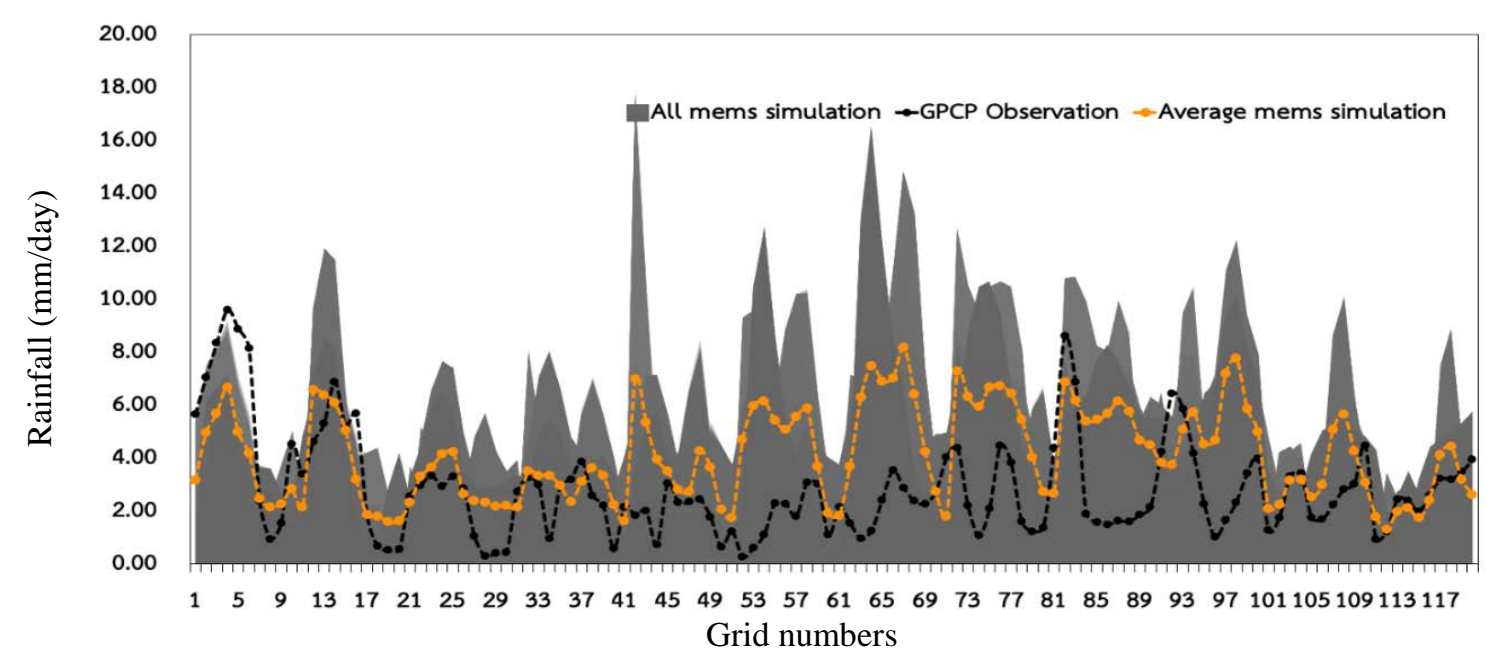

Fig. 5 The comparison rainfall value on April 2015 between results from average members bias correction Theorem 2 simulation (orange line) and GPCP observation data (black line) 


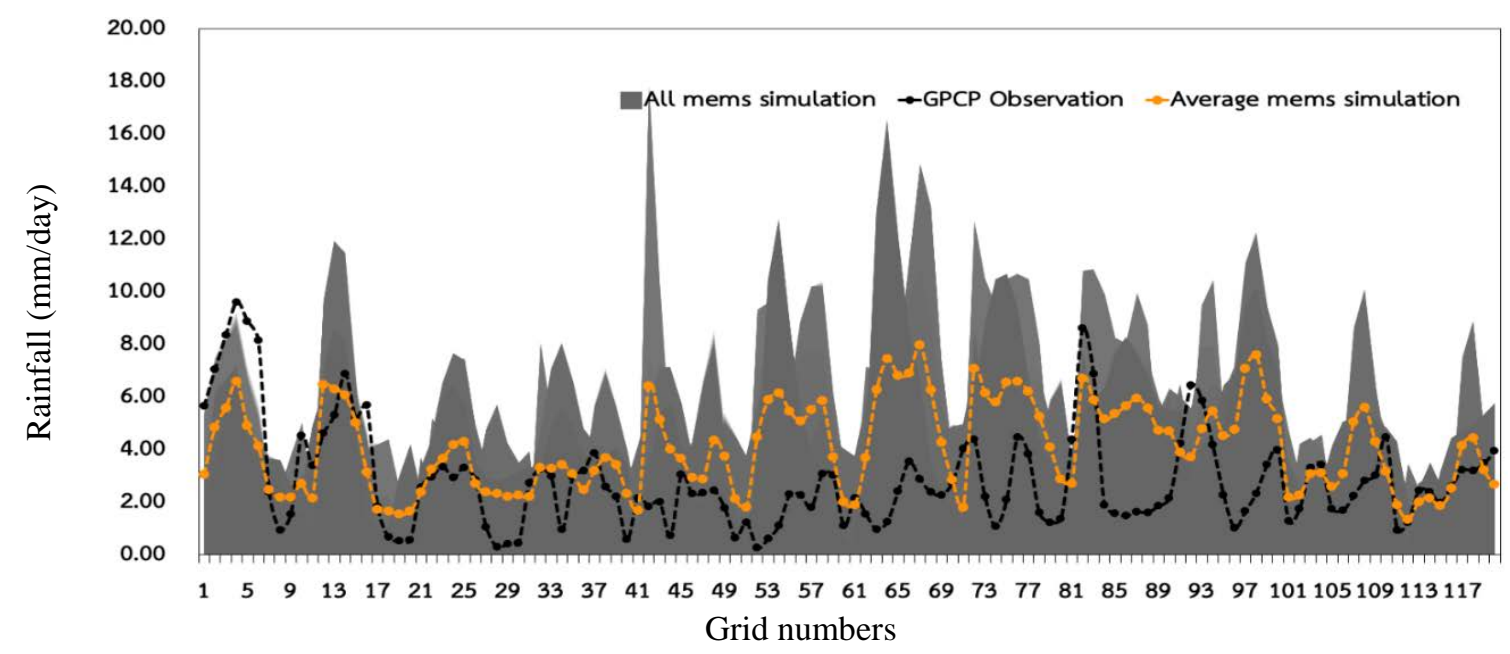

Fig. 6 The comparison rainfall value on April 2015 between results from average members bias correction Theorem 3 simulation (orange line) and GPCP observation data (black line)

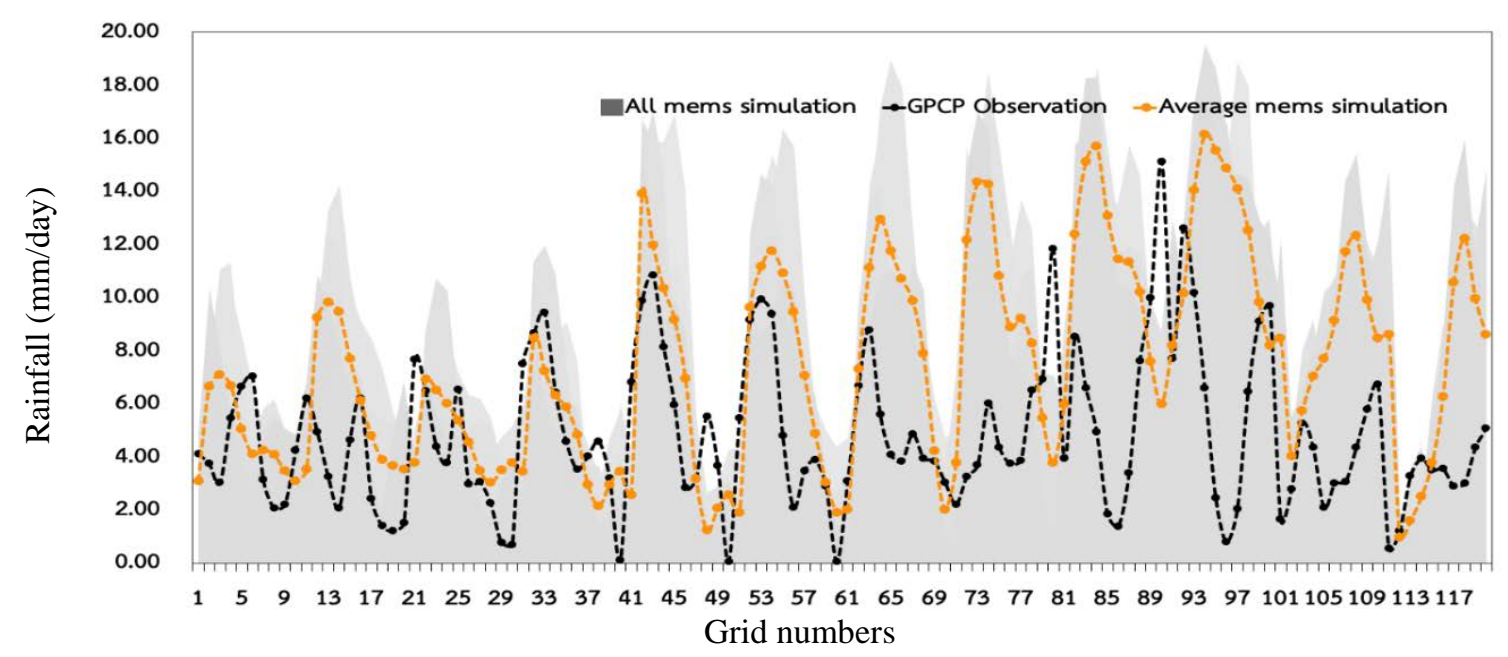

Fig. 7 The comparison rainfall value on May 2015 between results from average members model simulation (orange line) and GPCP observation data (black line)

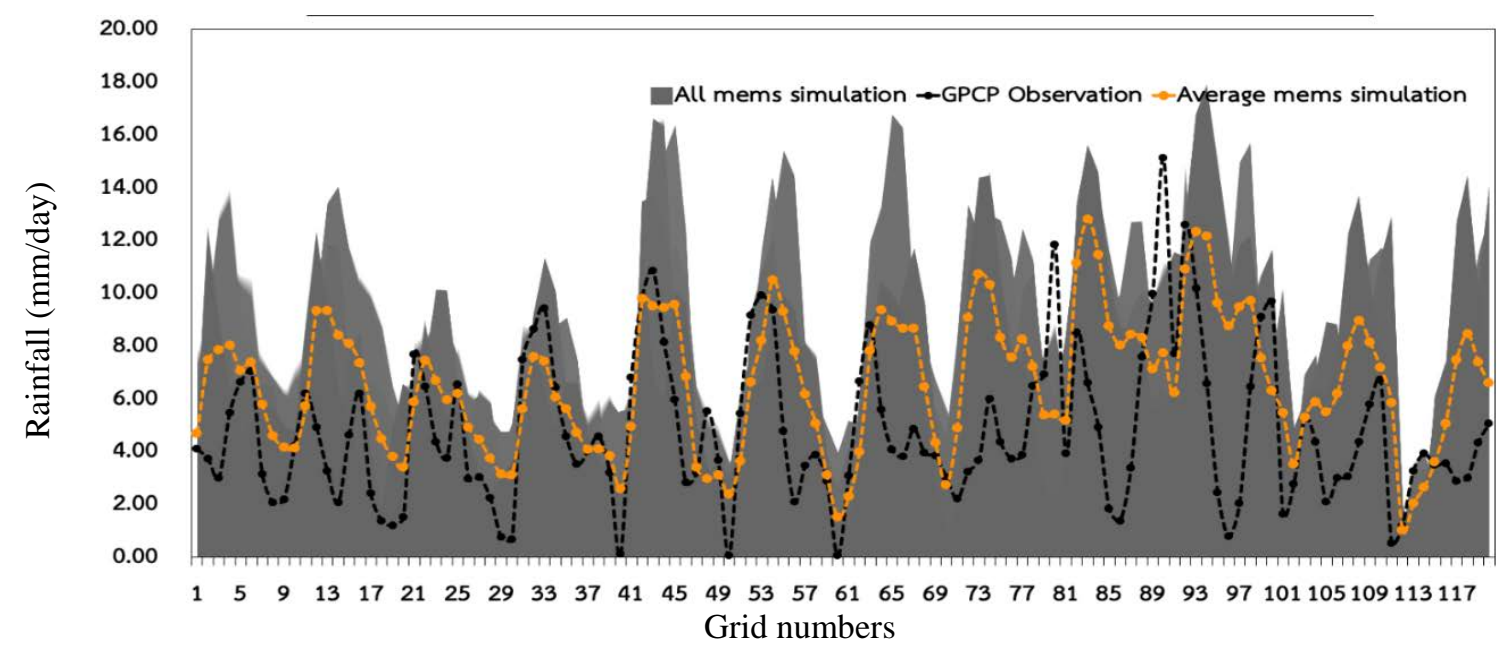

Fig. 8 The comparison rainfall value on May 2015 between results from average members bias correction Theorem 2 simulation (orange line) and GPCP observation data (black line) 


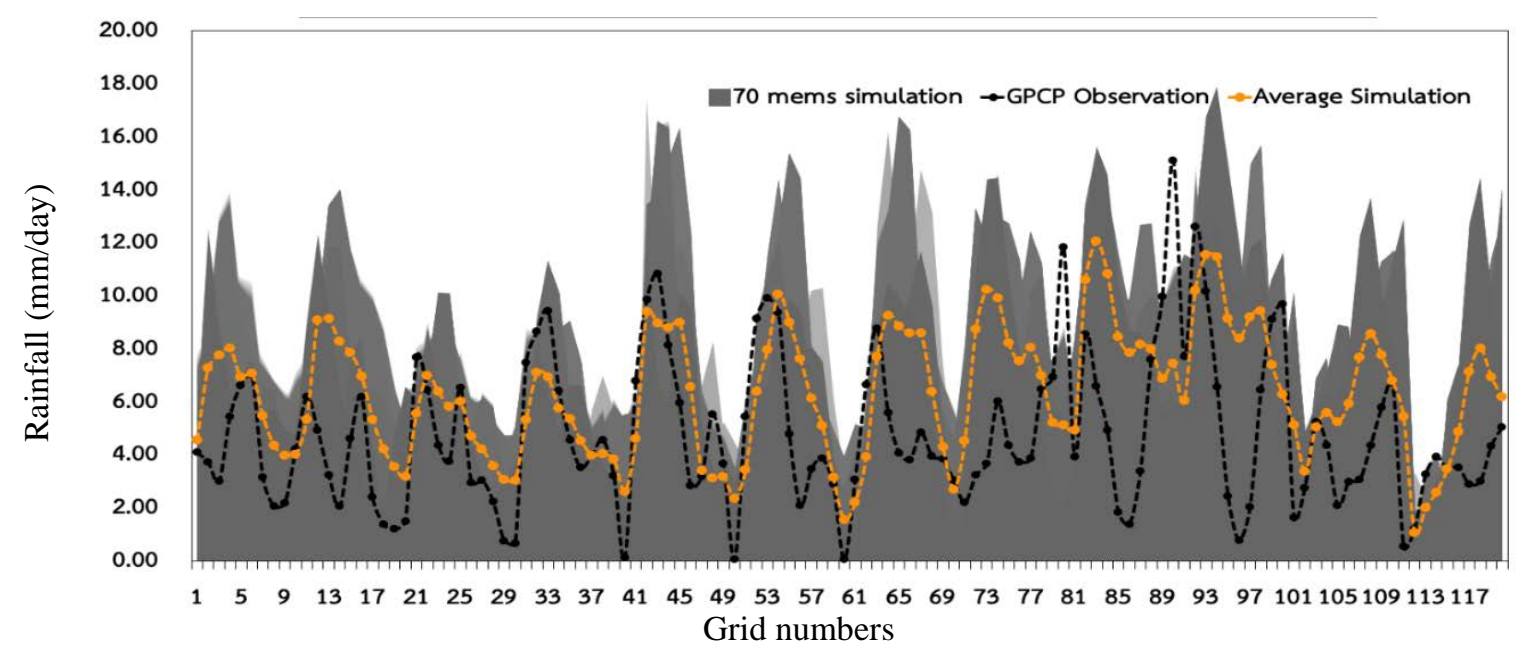

Fig. 9 The comparison rainfall value on May 2015 between results from average members bias correction Theorem 3 simulation (orange line) and GPCP observation data (black line)

In a statistical analysis, as shown in Table 1 , the average rainfall from bias correction (Theorem 2 and Theorem 3) was shown value close to model simulation. For example, in March 2015, the observation data recorded rainfall at $3.28 \mathrm{~mm} /$ day. The bias correction of Theorem 2 and Theorem 3 were recorded at $2.73 \mathrm{~mm} /$ day and $2.72 \mathrm{~mm} /$ day, respectively. On the other hand, the standalone model simulation recorded at $3.28 \mathrm{~mm} /$ day. For $M A E$ and RMSE cases, the results from bias correction were shown more accuracy than model simulation. For example, in May 2015 case, the bias correction decreased MAE of the model from 3.79 to 2.71 (decreased 1.08) by Theorem 2 and from 3.79 to 2.58 (decreased 1.21). In the case of RMSE, the bias correction decreases RMSE of the model from 4.23 to 2.87 (decrease 1.36) by Theorem 2 and from 4.23 to 2.84 (decrease 1.39) by Theorem 3 . The results from the time sires and statistical analysis were guaranteed the bias correction that can improve the results of the model and increase more accuracy than the results from the model when compared with reanalysis observation data.

Table 1. Statistical analysis between observation, model, Theorem 2, and Theorem 3.

\begin{tabular}{|c|c|c|c|c|c|}
\hline & & $\begin{array}{c}\text { Average Rainfall } \\
\text { (Obs. }=1.07 \mathrm{~mm} / \text { day) }\end{array}$ & $\begin{array}{c}\text { Bias } \\
\text { (Obs.-Model) }\end{array}$ & MAE & RMSE \\
\hline \multirow{3}{*}{$\begin{array}{c}\text { March } \\
2015\end{array}$} & Model & $3.28 \mathrm{~mm} /$ day & -2.21 & 2.33 & 2.23 \\
\hline & Theorem 2 & 2.73 mm/day & -1.66 & 1.76 & 1.24 \\
\hline & & $\begin{array}{c}\text { Average Rainfall } \\
\text { (Obs. }=2.84 \mathrm{~mm} / \mathrm{day})\end{array}$ & $\begin{array}{c}\text { Bias } \\
\text { (Obs.-Model) }\end{array}$ & $M A E$ & RMSE \\
\hline \multirow{3}{*}{$\begin{array}{c}\text { April } \\
2015\end{array}$} & Model & $4.94 \mathrm{~mm} /$ day & -2.10 & 2.90 & 3.20 \\
\hline & Theorem 3 & $4.08 \mathrm{~mm} /$ day & -1.25 & 1.97 & 2.17 \\
\hline & & $\begin{array}{c}\text { Average Rainfall } \\
\text { (Obs. }=4.79 \mathrm{~mm} / \text { day) }\end{array}$ & $\begin{array}{c}\text { Bias } \\
\text { (Obs.-Model) } \\
\end{array}$ & $M A E$ & RMSE \\
\hline \multirow{3}{*}{$\begin{array}{l}\text { May } \\
2015\end{array}$} & Model & $7.43 \mathrm{~mm} /$ day & -2.64 & 3.79 & 4.23 \\
\hline & Theorem 2 & $6.59 \mathrm{~mm} /$ day & -1.80 & 2.71 & 2.87 \\
\hline & Theorem 3 & $6.35 \mathrm{~mm} /$ day & -1.56 & 2.58 & 2.84 \\
\hline
\end{tabular}

\section{CONCLUSION}

In conclusion, this study developed the Lyapunov theorem to improve decaying average bias correction. The results from the standalone model were used in the bias correction method with Theorem 2 and Theorem 3 from IAP-AGCM. The observation data were used to compare with model and bias correction results from GPCP data. From the results, the times series results were shown the results from bias correction (Theorem 2 and
Theorem 3) that improved the results from the model and can approve the results closely than standalone model simulation. Such as on March 2015, over grid number 15, grid number 25 and grid number 33, the rainfall value of bias correction (Theorem 2 (Fig. 2) and Theorem 3 (Fig. 3)) decrease from around $6 \mathrm{~mm} /$ day to around 4 $\mathrm{mm} /$ day. In statistical analysis, the bias correction (Theorem 2 and Theorem 3) were shown the highest accuracy (MAE and RMSE) than only model simulation. For example, in May 2015 case, the bias 
correction decreased MAE of the model from 3.79 to 2.71 (decreased 1.08) by Theorem 2 and from 3.79 to 2.58 (decreased1.21) by Theorem 3. In the case of RMSE, the bias correction decreases RMSE of the model from 4.23 to 2.87 (decrease 1.36) by Theorem 2 and from 4.23 to 2.84 (decrease 1.39) by Theorem 3. However, the results from the time sires and statistical analysis were guaranteed the bias correction Lyapunov theorem that can improve the results of the model and increase more accuracy than the results from the standalone model when compared with reanalysis observation data.

\section{ACKNOWLEDGMENTS}

The authors acknowledge King Mongkut's University of Technology Thonburi for funding Postdoctoral Fellowship to Dr.Pramet Kaewmesri. The authors are very grateful to the Department of Mathematics, Faculty of Science for all support.

\section{REFERENCES}

[1] Cronin, J., Differential Equations: Introduction and Qualitative Theory. Marcel Dekker, New York, 1994

[2] Sanchez. D.A., Ordinary Differential Equations and Stability Theory: An Introduction. Dover Publications, New York, 1979

[3] Humphries, U., Kaewmesri, P., Wongwises, P., Archevarapuprok, B., Sooktawee, S., Simulation of Large Scale Resolution IAP DCP Model for Pre-Monsoon and Southwest Monsoon Events over Indo China Peninsular. Vol 13, 2018, pp. 94-102

[4] Humphries, U., Kaewmesri, P., Varnakovida, P., Wongwises, P., Improvement in rainfall estimates using bias correction with the IAPDCP Global Model. Vol 171, 2020, pp. 26-35

[5] Humphries, U., Kaewmesri, P., Varnakovida, P., Rainfall trend by linear regression analysis over Indochina Peninsula during 1981-2017 (37 Years). Vol 15, 2018, pp. 206-213

[6] Albrecht, B.A., Ramanathan, V., Boville A., The effects of cumulus moisture transports on the simulation of climate with a general circulation model. American Meteor Society. Vol 43, 1986, pp. 2443-2462
[7] Adler, R.F., Huffman, G.J., Chang, A., Ferraro, R., Xie, P., Janowiak, J., Rudolf, B., Schneider, U., Curtis, S., Bolvin, D., Gruber, A., Susskind, J., Arkin, P., Nelkin, E., The version 2 Global Precipitation Climatology Project (GPCP) monthly precipitation analysis (1979-present). J. Hydrometeor, Vol 4, 2003, pp. 1147-1167

[8] Adler, R.F., Gu, G., Huffman, G., Estimating Climatological Bias Errors for the Global Precipitation Climatology Project (GPCP). Journal of Applied Meteorology and Climatology, Vol 51, 2012, pp. 84-99.

[9] Cui, B., Toth, Z., Zhu, Y., Hou, D., Bias correction for global ensemble forecast. Weather and Forecasting. Vol27, 2012, pp. 396410

[10] Xinzhong, L., Description of a nine-level grid point atmospheric general circulation model. Advance in Atmospheric Science. Vol 13, 1996, pp. 269-298

[11]Kaewmesri P., Humphries U., Wangwongchai A., Wongwises P., Archevarapuprok B., Sooktawee S., The simulation of heavy rainfall events over Thailand using microphysics schemes in weather research and forecasting (WRF) model. World Applied Sciences Journal. Vol 35, 2017a, pp. 310-315

[12]Kaewmesri P., Humphries U., Sooktawee S., Simulation on High-Resolution WRF Model for an Extreme Rainfall Event over the Southern Part of Thailand. International Journal of Advanced and Applied Sciences. Vol 4, 2017b, pp. 26-34

[13]Kaewmesri P., Humphries U., Simulation of an unseasonal heavy rainfall event over southern Thailand using the Weather Research and Forecasting (WRF) model. SAUSSUREA. Vol 8, 2018a, pp. 1-18

[14]Kaewmesri P., Humphries U., Archevarapuprok B., Sooktawee S., The Performance Rainfall during Rainy Seasonal over Thailand by using Preliminary Regional Coupled Atmospheric and Oceanic (WRFROMS) Model. International Journal of GEOMATE. Vol 14, 2018b, pp. 109-115.

Copyright @ Int. J. of GEOMATE. All rights reserved, including the making of copies unless permission is obtained from the copyright proprietors. 